\title{
EFFECT OF MULTIPARITY ON SEROTONIN AND OXYTOCIN HORMONES COMPARED TO PRIMIPARITY AND NULLIPARITY IN PREGNANT SUDANESE WOMEN
}

\author{
Mutasem Mahmoud Abdallah Ahmed ${ }^{1}$,Kamal Ahmed Abdelsalam², Mutaz Ibrahim Hassan ${ }^{3}$ \\ 1 Department of Clinical Chemistry, Faculty of Medical Laboratory Sciences-Shendi University, Sudan. \\ 2Department of Clinical Laboratory Sciences, Applied Medical College, Shaqra University. \\ ${ }^{3}$ Department of Clinical Chemistry, Faculty of Medical Laboratory Sciences-Shendi University, Sudan.
}

\begin{tabular}{l}
\hline BBSTRACT \\
HyCKGROUND \\
as well as pro-social hormone oxytocin regulation. This study aimed to compare the levels of these hormones in multiparity, with \\
primiparity and nulliparity.
\end{tabular}

\section{MATERIAL AND METHODS}

This case control study included three hundred women aged 20-48 years from two hospitals in Khartoum state. Women were grouped into three groups comprising multiparity, primiparity and nulliparity. Questionnaires were administered to the women and their blood samples were collected via vein puncture in early morning (8:00 - 11:00 am); after centrifugation of the blood samples, the sera were analysed for serotonin and oxytocin levels by using fully-automated ELISA. The sample size required was taken for convenience.

\section{RESULTS}

it was found that the serotonin and oxytocin levels showed significant changes in multiparity compared to nulliparity as well as primiparity ( $p$ value $<0.05$ ). In multiparity, serotonin and oxytocin levels showed significant changes when classified according to age ( $p$ value $<0.05$ ). Levels of serotonin as well as oxytocin in multiparous pregnant women increased with age. Never the less, body mass index (BMI) of multiparity women exhibited insignificant changes on both serotonin and oxytocin levels (p value $>$ 0.05). In multiparity, oxytocin levels showed significant changes when classified according to the delivery type ( $p$ value $<0.05$ )

\section{CONCLUSION}

Clinically, multiparity is associated with significant variation in serotonin and oxytocin levels in pregnant women.

\section{KEY WORDS}

Multiparity, Primiparity, Nulliparity, Serotonin, Oxytocin.

HOW TO CITE THIS ARTICLE: Ahmed MMA, Abdelsalam KA, Hassan MI. Effect of multiparity on serotonin and oxytocin hormones compared to primiparity and nulliparity in pregnant Sudanese women. J. Evolution Med. Dent. Sci. 2019;8(08):478-481, DOI: $10.14260 /$ jemds/2019/106

\section{BACKGROUND}

In medicine, parity is the number of times a female has been pregnant and carried the pregnancies to a viable gestational age.[1] A woman who has given birth two or more times is called a multipara; while grand multipara describes the condition of having given birth five or more.[2] Grand multiparity has been considered an independent factor for increasing adverse outcome for both fetus and mother specially diabetes mellitus, antepartum haemorrhage, malpresentation, caesarean section rate, postpartum haemorrhage, iron deficiency anaemia, and a high perinatal mortality rate.[3] More recent reports, however, have demonstrated that in the presence of good perinatal care, grand multiparity no longer need to be considered an obstetrical risk in the presence of satisfactory health care conditions. ${ }^{[4]}$

'Financial or Other Competing Interest': None.

Submission 27-09-2018, Peer Review 08-02-2019,

Acceptance 15-02-2019, Published 25-02-2019.

Corresponding Author:

Mutasem Mahmoud Abdallah Ahmed,

Khartoum-Sudan.

Department of Clinical Chemistry,

Faculty of Medical Laboratory Sciences-Shendi University, Sudan.

E-mail: mutasemlab3@gmail.com

DOI: $10.14260 /$ jemds $/ 2019 / 106$

\section{(c) (i) $\$$}

The majority of the studies argued that grand multiparas are more likely to be of old age which might be the reasons for increased morbidity and mortality. Such factor is difficult to be removed clinically because women's age is the most important biological variable that influences the reproductive health issue.[5] A few previous studies have shown that maternal grand multiparity may predict an increased risk of psychopathology in adult offspring.[6-7] These studies have shown that offspring born as a fourth or later born -child have higher risks of psychiatric hospitalizations for any reason, and that offspring born as a third or later-born child have an increased risk of personality and behavioural disorders in adult life ${ }^{[8]}$. However, it remains unknown if the risks associated with maternal grand multiparity for mental disorders in the offspring persist after the transition into adulthood and to a more independent role in the society. It is also uncertain if maternal grand multiparity is independently associated with the risk of mental disorders or whether the associations found are confounded by maternal age at childbirth.[7]

In most cases, the changes in women's metabolism during pregnancy are a good thing they ensure a balance of health for both mother and fetus. But unfortunately in a recent study, almost all pregnant women have been noted to have changes in oxytocin and serotonin levels, overwhelmingly leading to abrupt and frequent changes in emotional state.[9] 
Serotonin hormone or 5-hydroxytryptamine (5-HT) is fundamentally neurochemical molecule in brain cells, or neurons, when released makes human feel good when having something beneficial for survival. There is no evidence that serotonin directly underpins happiness. Over the past few decades, researchers have been discussing that mental health issues such as depression and anxiety might fundamentally be disorders of learning, rather than outcomes of a 'chemical imbalance' that requires correction by serotonin boost.[10] Whereas, oxytocin secreted from the pituitary gland cannot re-enter the brain because of the blood-brain barrier. Instead, the behavioural effects of oxytocin are thought to reflect release from centrally projecting oxytocin neurons, different from those that project to the pituitary gland.[11] Some popular media have labelled it the "love hormone," because it has sophisticatedly association with good feelings and emotions. It does appear to be connected to human emotions.[12] According to recent research, this hormone "is now believed to be involved in a wide variety of physiological and pathological functions such as maternal behaviour.[13]

And therefore, the aim of this study was to estimate effect of multiparity pregnant on serotonin and oxytocin hormones compared to primiparity and nulliparity in Sudanese women.

\section{MATERIALS AND METHODS}

This study was designed to be a comparative cross sectional study, this study was conducted in Khartoum State, Jabal Awlia Hospital, and Omdurman Maternity Hospital. The study was carried out during the period from September 2016 to April 2019. Three hundred women were enrolled in this study; 100 were multiparity pregnant women as study group, 100 were primiparity pregnant women as control positive group and 100 were nulliparity (Non-pregnant women) were the control negative group. The sampling technique used was convenience sampling. All participants were in their fertility period and/or premenopausal period, in age of 20-48 years old. Women were grouped into three groups comprising multiparity, primiparity and nulliparity. Questionnaires were administered. The demographic data like name, age, parity, gestational age, height, tall and BMI. Blood samples were collected via vein puncture in early morning (8:00-11:00 am). After centrifugation of blood sample, the sera were analysed for serotonin and oxytocin hormones levels by using full-automated ELISA. All pregnant women were at 26-34 weeks gestational age. Since the duration of the study was less. The women were selected by convenience sampling technique. The sample size required was taken for convenience.

\section{Ethical Considerations}

This study was approved by the research committee - College of Medical Laboratory Sciences-Shandi University. Informed consent was obtained from each participant before taking the samples.

\section{Methods of BMI Estimation}

It calculates a value indicative of the fat content of the body by dividing the weight by the square of height [14]

\begin{tabular}{|c|c|}
\hline Categories & BMI \\
\hline Under Weight & Less Than 18.5 \\
\hline Normal Weight & $18.5-24.9$ \\
\hline Over Weight & $25-29.9$ \\
\hline Obese & 30 or Higher \\
\hline \multicolumn{2}{|c}{ BMI Categories } \\
\hline
\end{tabular}

All pregnant women take drugs that have effect on estimation and/or with major hormonal disorder along with those refused to participate in this study were excluded.

\section{Sampling Procedure}

Venous blood was collected using antiseptic for the skin, as well as data concerning any sample from clinical chemistry laboratories according to Inclusion criteria and exclusion criteria. Seven ml venous blood samples were obtained from each female using standard venipuncture technique[15] in serum separator tubes (SST). After 15 minutes, serum specimens were collected in plane container after centrifugation at $3000 \mathrm{rpm}$ for 5 minutes. The serum stored frozen $\left(-20^{\circ} \mathrm{C}\right)$ in a tightly sealed tube for only 2 weeks and then analyzed. Specimens should be allowed to come to room temperature and then mixed thoroughly by gentle inversion before assaying. Then serotonin and oxytocin were measured by automated Enzyme-Linked Immunosorbent Assay (ELISA) kit.

\section{Quality Controls and Managements}

Blood was collected with care and adequate safety precautions to ensure test results were reliable. Quality Assurance (QA) and standard Operating System was followed for all biological and clinical tests to achieve validity and reliability of test results.

\section{Statistical Analysis}

All data are presented as mean \pm SD. Statistical significance was determined using one-way ANOVA followed by Tukey's multiple comparison test. In results with only two set of data, unpaired student's test with Welch correction (Unequal sample size) was used. Though the SD values were high in some parameters, ANOVA was used as it has been reported to be robust for different types of data.[16]

\section{RESULTS}

\begin{tabular}{|c|c|c|c|}
\hline Parameters & Nulliparity & Primiparity & Multiparity \\
\hline Serotonin & $236 \pm 103$ & $85.4 \pm 71^{* * *}$ & $96 \pm 66^{* * *}$ aaa \\
\hline Oxytocin & $236 \pm 288$ & $356 \pm 369^{* * *}$ & $\begin{array}{c}783 \pm \\
1126.8^{* *} \text { aaa }\end{array}$ \\
\hline BMI & $23.5 \pm 1.5$ & $28.0 \pm 3.15^{* *}$ & $28.0 \pm 3.5^{*}$ \\
\hline Age & $32.1 \pm 2.7$ & $25.5 \pm 3.6^{* *}$ & $30.2 \pm 4.0^{* * *}$ aaa \\
\hline Table 1. Statistics of Demographic Data and Biochemical \\
Parameters \\
\hline \multicolumn{4}{|c|}{$\begin{array}{c}\text { Age values are mean } \pm \text { SD, Serotonin, Oxytocin hormones and } \\
\text { BMI value are Median } \pm \mathrm{IQR}{ }^{*} \mathrm{P}<0.05{ }^{* *} \mathrm{P}<0.01,{ }^{* * *} \mathrm{P}<0.001 \\
\text { compared to nulliparity, aaaP }<0.001 \text { compared to primiparity }\end{array}$} \\
\hline
\end{tabular}

$\mathrm{BMI}=\frac{\operatorname{mass}(\mathrm{kg})}{(\operatorname{height}(\mathrm{m}))^{2}}$ 

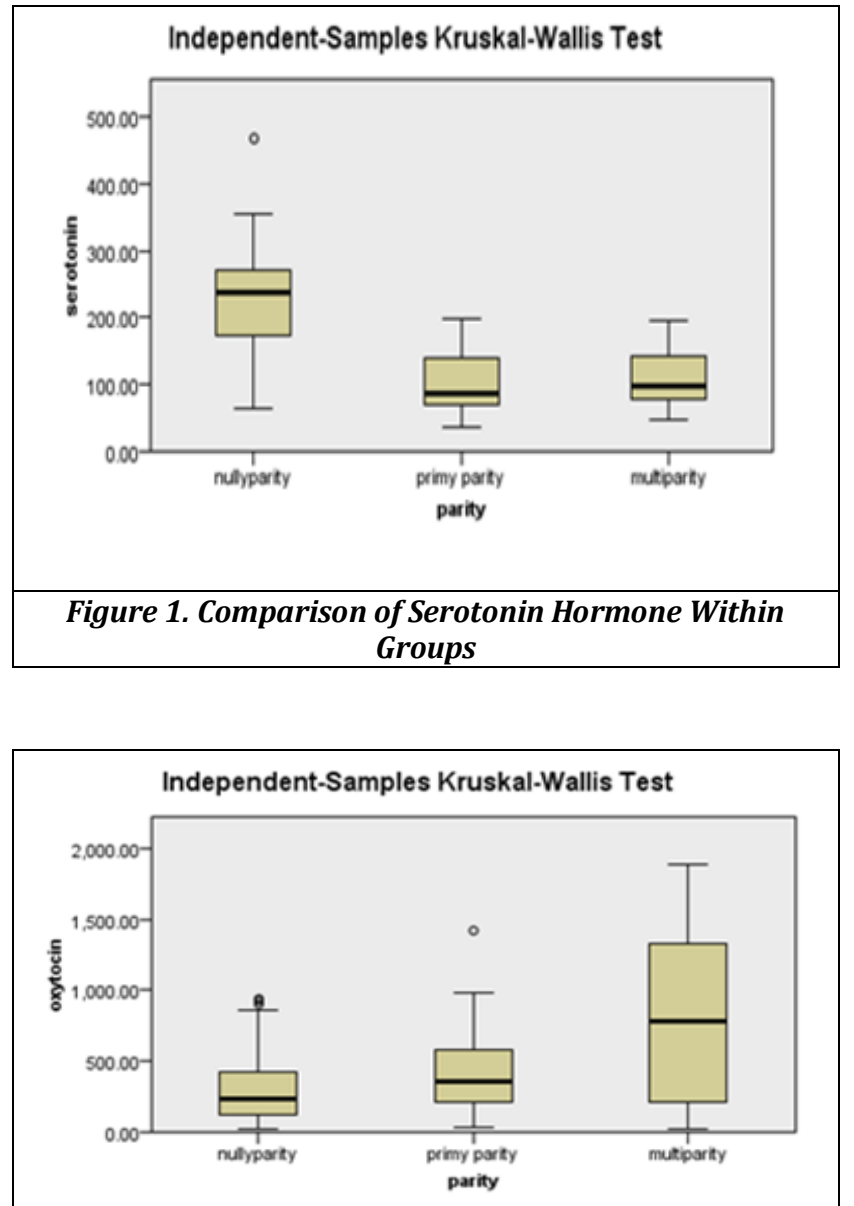

Figure 2. Comparison of Oxytocin Hormone Within Groups

Table 1, Figure 1, Figure 2 shows the statistics of demographic data and biochemical parameters computed for the three groups (Nulliparity, Primiparity and Multiparity). The results showed that there is statistical significance difference between the groups means for all parameters respectively.

\begin{tabular}{|c|c|c|c|c|c|c|}
\hline \multirow{2}{*}{ Parameters } & \multicolumn{2}{|c|}{ Multiparity } & \multicolumn{2}{c|}{ Primiparity } & \multicolumn{2}{c|}{ Nulliparity } \\
\cline { 2 - 7 } & $\mathbf{r}$ & $\begin{array}{c}\mathbf{p} \\
\text { Value }\end{array}$ & $\mathbf{r}$ & $\begin{array}{c}\mathbf{p} \\
\text { Value }\end{array}$ & $\mathbf{r}$ & $\begin{array}{c}\mathbf{p} \\
\text { Value }\end{array}$ \\
\hline Age - Serotonin & 0.101 & 0.153 & $0.022-$ & 0.829 & 0.035 & 0.728 \\
\hline Age - Oxytocin & 0.220 & 0.002 & -0.041 & 0.689 & -0.129 & 0.200 \\
\hline $\begin{array}{c}\text { BMI - } \\
\text { Serotonin }\end{array}$ & 0.041 & 0.565 & 0.053 & 0.597 & -0.094 & 0.352 \\
\hline BMI - Oxytocin & -0.003 & 0.964 & -0.093 & 0.356 & -0.001 & 0.992 \\
\hline $\begin{array}{c}\text { Table 2. Spearman Correlation Coefficient (R) Between } \\
\text { Demographic Data and Biochemical Parameters Within } \\
\text { Groups }\end{array}$ \\
\hline
\end{tabular}

Table 2. There was a weak positive correlation between oxytocin and age among multiparous women. This correlation was found to be statistically significant.

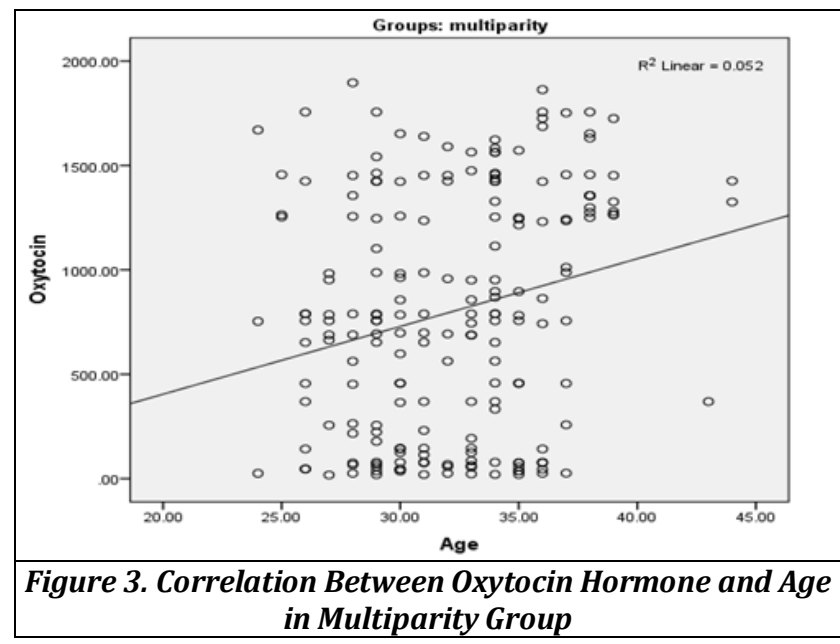

\section{DISCUSSION}

The pregnancy is associated with many physiological and morphological changes to suit the needs of the growing fetus. These changes accompanying pregnancy are feared to have deleterious effects for mother and baby as the number of gestations.

In the present study, the results revealed that the mean concentration of the serotonin and oxytocin in multiparity pregnant women were significantly altered as compared to nulliparity women as well as primiparity pregnant women ( $\mathrm{p}$ value<0.001).

Previous studies had further expands on this pattern, by reporting strong and significant rank-order correlations for within-subject oxytocin levels for all three time-periods, covering a 6 month epoch and spanning two distinct phases, pregnancy and the early post partum.[17]

In the present study the results showed that for age there is statistical significance difference between the groups means for all parameters $(\mathrm{P}=<0.001)$, for $\mathrm{BMI}$ and serotonin in there no statistical significance difference between multiparity and nulliparity respectively. Also, for oxytocin there is no statistical significance difference primiparity and nulliparity.

In the present study the correlation of oxytocin and serotonin means with age and BMI within the three groups. The results showed that for multiparity there is statistical significance difference between (age and oxytocin $\mathrm{P}=0.002$ ).

Previous studies concluded that significant age-related changes in the female hormonal environment occur during the reproductive years. [18]

Nevertheless, previous studies were showed that multiparity is a risk factor for obesity in later life either before or after menopause and definitely real association between the number of parities and obesity was noticed.[19]

\section{CONCLUSION}

Levels of oxytocin hormones are significantly affected by multiparty and the age of pregnant women.

\section{REFERENCES}

[1] Borton AB. Chloe (November 12, 2009). "Gravidity and Parity Definitions (and their Implications in Risk Assessment)". Patient.info. Retrieved June 26, 2013.

[2] Cunningham $F$, Leveno $\mathrm{K}$, Bloom $\mathrm{S}$, et al. Williams obstetrics. 22nd edn. McGraw-Hill Companies 2005. 
[3] Al JF. Grand multiparity: a potential risk factor for adverse pregnancy outcomes. J Reprod Med 2012;57(1-2):53-7.

[4] Kumari AS, Badrinath P. Extreme grand multiparity: is it an obstetric risk factor? Eur J Obstet Gynecol Reprod Biol 2002;101(1):22-5.

[5] Kaplan B, Harel L, Neri A, et al. Great grand multiparity--beyond the 10th delivery. Int J Gynaecol Obstet 1995;50(1):17-9.

[6] Alaräisänen A, Miettunen J, Pouta A, et al. Ante- and perinatal circumstances and risk of attempted suicides and suicides in offspring: the Northern Finland birth cohort 1966 study. Soc Psychiatry Psychiatr Epidemiol 2012;47(11):1783-94.

[7] Keskinen E, Miettunen J, Koivumaa-Honkanen H, et al. Interaction between parental psychosis and risk factors during pregnancy and birth for schizophrenia the Northern Finland 1966 Birth Cohort study. Schizophr Res 2013;145(1-3):56-62.

[8] Fazel S, Bakiyeva L, Cnattingius S, et al. Perinatal risk factors in offenders with severe personality disorder: a population-based investigation. J Pers Disord 2012;26(5):737-50.

[9] Field T, Diego M, Hernandez-Reif M, et al. Prenatal serotonin and neonatal outcome: brief report. Infant Behav Dev 2008;31(2):316-20.

[10] Caspi A, Sugden K, Moffitt TE, et al. Influence of life stress on depression: moderation by a polymorphism in the 5-HTT gene. Science 2003;301(5631):386-9.
[11] Zak PJ, Stanton AA, Ahmadi A. Oxytocin increases generosity in humans. PLoS One 2007;2(11):e1128.

[12] Kosfeld M, Heinrichs M, Zak PJ, et al. Oxytocin increases trust in humans. Nature 2005;435(7042):673-6.

[13] Stanton AA. Neural substrates of decision-making in economic games. Scientific Journals International 2007;1(1):1-64.

[14] Sarah B. Encyclopedia of Epidemology. SAGE Publications Inc 2008:115-8.

[15] Clinical Laboratory Standards Institute. Procedures for the collection of diagnostic blood specimens by venepuncture: approved standard. CLSI H3-A6 document. $6^{\text {th }}$ edn. Wayne, PA: Clinical Laboratory Standards Institute 2007.

[16] Blanca MJ, Alarcón R, Arnau J, et al. Non-normal data: Is ANOVA still a valid option? Psicothema 2017;29(4):552-7.

[17] Levine A, Zagoory-Sharon O, Feldman R, et al. Oxytocin during pregnancy and early postpartum: individual patterns and maternal-fetal attachment. Peptides 2007;28(6):1162-9.

[18] Musey VC, Collins DC, Musey PI, et al. Age-related changes in the female hormonal environment during reproductive life. Am J Obstet Gynecol 1987;157(2):312-7.

[19] Hajiahmadi M, Shafi H, Delavar MA. Impact of parity on obesity: a cross-sectional study in Iranian women. Med Princ Pract 2015;24(1):70-4. 